\title{
Biomechanical stress-induced apoptosis in vein grafts involves p38 mitogen-activated protein kinases
}

\author{
MANUEL MAYR,* CHAOHONG LI,* YIPING ZOU,* URSULA HUEMER, ${ }^{\dagger}$ YANHUA HU, ${ }^{+}$ \\ AND QINGBO XU*,1 \\ *Institute for Biomedical Aging Research, Austrian Academy of Sciences, Innsbruck; and ${ }^{\dagger}$ Institute \\ for General and Experimental Pathology, University of Innsbruck, Medical School, Innsbruck
}

ABSTRACT The present study was designed to investigate whether apoptosis occurs in early-stage vein grafts and to determine the mechanisms by which mechanical stress contributes to apoptosis in vascular smooth muscle cells (SMCs). Apoptosis in vessel walls of mouse vein grafts was confirmed by morphological changes and by terminal deoxynucleotidyl transferasemediated dUTP-biotin nick end labeling (TUNEL). TUNEL $^{+}$cells in vein grafts 1,4 , and 8 wk postoperatively was $13 \%, 29 \%$, and $21 \%$, respectively, and apoptosis occurred mainly in veins grafted to arteries, remaining unchanged in vein-to-vein grafts. When mouse, rat, and human arterial SMCs were cultured on a flexible membrane and subjected to cyclic strain stress, apoptosis was observed in a time- and strengthdependent manner. All three types of SMCs showed apoptotic death as confirmed by TUNEL, propidium iodide, and annexin V staining. To further study the signal pathways leading to apoptosis, activities of p38, a subfamily of mitogen-activated protein kinases (MAPKs), were determined. Mechanical stress resulted in p38 MAPK activation, reaching high levels within 8 min. SB 202190, a specific inhibitor for p38 MAPKs, prevented SMC apoptosis in response to mechanical stress. SMC lines stably transfected with a dominant negative rac, an upstream signal transducer, or overexpressing MAPK phosphatase-1, a negative regulator for MAPKs, completely inhibited mechanical stress stimulated p38 activation and abolished mechanical stressinduced apoptosis. Thus, we provide solid evidence that one of the earliest events in venous bypass grafts is apoptosis, in which mechanical stress-induced p38MAPK activation is responsible for transducing signals leading to apoptosis.-Mayr, M., Li, C., Zou, Y., Huemer, U., Hu, Y., Xu, Q. Biomechanical stress-induced apoptosis in vein grafts involves p38 mitogen-activated protein kinases. FASEB J. 15, 261-270 (2000)

Key Words: MAPKs $\cdot$ smooth muscle cell $\cdot$ propidium iodide - cytokine

THE SMALL CALIBER autogenous saphenous vein is often used for grafting, but occlusion of the grafted vein diminishes the patency rate after bypass opera- tions (1). Vein grafts become occluded when abnormal cell proliferation in the smooth muscle layer and extra tissue production in the inner lining of the vessel thicken the vessel wall in response to the new high-pressure circulation that the grafted vein must withstand (2). Most studies of the pathogenesis of vein graft arteriosclerosis focused on smooth muscle cell (SMC) proliferation (3). In fact, an extensive loss of endothelial cells and a significant loss of SMCs were observed in the intima and media at the early stage of vein grafts, but little is known about the molecular mechanisms and the role of cell death or apoptosis in the pathogenesis of vein graft arteriosclerosis (4).

Apoptosis, or programmed cell death, can be induced by cytokines (5), conflicting signals, and DNA damage (6), but it remains to be clarified whether biomechanical stress itself can cause apoptosis in vascular SMCs. The grafted veins are subjected to increased biomechanical forces in the form of stretch stress due to blood pressure and shear stress due to blood flow (7). While shear stress is primarily sensed by endothelial cells, tension stress exposes all vascular cell types to cyclic mechanical strain due to the pulsatile nature of blood flow. The sudden elevation in mechanical forces could be a strong stimulus to the grafted vessel wall and may result in activation of intracellular signal pathways leading to gene expression, cell death, or cell proliferation (7).

Mitogen-activated protein kinases (MAPKs), a family of serine/threonine kinases, encompass the extracellular signal-regulated kinases (ERKs), c-Jun $\mathrm{NH}_{2}$ terminal protein kinases (JNKs) or stress-activated protein kinases (SAPKs), and p38 MAPKs (8-11). They are thought to play a critical role in regulating cellular events required for cell growth, differentiation, and apoptosis (8-11). MAPKs are strongly activated in the arterial wall in response to angioplasty (12), acute hypertension (13), and low-density

\footnotetext{
${ }^{1}$ Correspondence: Institute for Biomedical Aging Research, Austrian Academy of Sciences, Rennweg 10, A-6020 Innsbruck, Austria. E-mail: Qingbo.Xu@oeaw.ac.at
} 
lipoproteins (14), which are known risk factors for vascular diseases. Recently we provided direct evidence that mechanical stress results in rapid activation of PDGF receptor-MAPK signal pathways, which could be important for understanding the role of biomechanical stress in the pathogenesis of vascular diseases (15).

We hypothesize that apoptosis in venous bypass grafts may occur as one of the earliest events after grafting, and that induction of cell death may be determined by mechanical stress. The objectives of the present study were to detect apoptosis in venous bypass grafts in vivo, to determine the role of mechanical stress for SMC apoptosis in vitro, and to establish a direct link between biomechanical stress stimulation and apoptosis in SMCs.

\section{MATERIALS AND METHODS}

\section{Mouse model of vein grafts}

All animal experiments were performed according to protocols approved by the Institutional Committee for Use and Care of Laboratory Animals. A mouse model of venous bypass grafts was established by grafting isogeneic venae cavae to common carotid arteries of C57BL/6J mice, as described previously (16). Briefly, C57BL/6J mice were used as donors and recipients. A segment (approx. $1 \mathrm{~cm}$ ) of vena cava was grafted end-to-end to carotid arteries using a cuff technique. The vein grafts were harvested at 1 day or at $1,2,4$, and $8 \mathrm{wk}$ postoperatively (four to eight randomly chosen mice at each time point) by cutting the implanted segments from the native vessels at the cuff end after mice were anesthetized and perfused with $0.9 \% \mathrm{NaCl}$ solution via cardiac puncture in the left ventricle and with $4 \%$ phosphate-buffered formaldehyde ( $\mathrm{pH}$ 7.2) for 3 and $5 \mathrm{~min}$, respectively.

\section{TUNEL assay}

Samples were fixed with $4 \%$ phosphate-buffered formaldehyde $(\mathrm{pH} 7.2)$ at $4^{\circ} \mathrm{C}$ for $24 \mathrm{~h}$. After fixation, the grafts were cut in middle of the vein segments, dehydrated in graded ethanol baths, cleared in xylol, and embedded in paraffin. Routinely, $7 \mu \mathrm{m}$-thick sections were made throughout the dissected fragments. Accumulated internucleosomal DNA fragments (apoptosis) were detected using an in situ apoptosis detection kit (Boehringer Mannheim Corp., Mannheim, Germany). Sections were dewaxed, rehydrated, fixed with $4 \%$ paraformaldehyde, and permeabilized by $0.1 \%$ Triton X-100/ $0.1 \%$ sodium citrate. Sections were incubated with fluorescein-conjugated dUTP and the enzyme terminal deoxyribonucleotide transferase, and stained with anti-fluorescein antibodies linked with alkaline phosphatase. Finally, sections were developed with Fast Red substrate and counterstained with hematoxylin. Percentages of positive stained cells were determined by counting the numbers of labeled and total cells using a light microscope (Axiophot, Zeiss). Positive cells of whole intima and media of control veins and $1 \mathrm{wk}$ grafts were counted and two regions of each section of 4 and 8 wk grafts. Morphological features of apoptosis were assessed on light and laser microscope in transmission scan mode (Microradiance, Bio-Rad).

\section{Cell culture}

SMCs were isolated by enzymatic digestion of aortas from rat, mice and humans, as described previously (17, 18), and cultured in DMEM (PAA Laboratories GmbH, Linz, Austria) supplemented with $20 \%$ fetal calf serum, penicillin (100 $\mathrm{U} / \mathrm{ml})$, and streptomycin $(100 \mu \mathrm{g} / \mathrm{ml})$. Cells were incubated at $37^{\circ} \mathrm{C}$ in a humidified atmosphere of $5 \% \mathrm{CO}_{2}$ and passaged by treatment with $0.05 \%$ trypsin $/ 0.02 \%$ EDTA solution. Experiments were conducted on SMCs achieving subconfluence at passages 7 to 15 .

\section{Cyclic strain stress}

SMCs were seeded on silicone elastomer-bottomed culture plates (Flexcell, McKeesport, Pa.) at $1.5 \times 10^{5}$ cells per well, grown for $48 \mathrm{~h}$ in medium with $20 \%$ fetal calf serum, and subjected to cyclic strain stress. The Cyclic Stress Unit, a modification of the unit initially described by Banes et al. (19), consisted of a computer-controlled vacuum unit and a base plate to hold the culture plates (FX3000 AFC-CTL, Flexcell). Vacuum (15 to $20 \mathrm{kPa}$ ) was repetitively applied to the elastomer-bottomed plates via the base plate. Cyclic deformation (60 cycles/min) with elongations ranging from 5 to $30 \%$ was applied for $10 \mathrm{~min}$ up to $6 \mathrm{~h}$ in a humidified incubator with $5 \% \mathrm{CO}_{2}$ at $37^{\circ} \mathrm{C}(15)$.

\section{Annexin V staining}

Annexin staining was performed according to the manufacturer's instructions (PharMingen, San Diego, Calif.). In brief, adherent SMCs were trypsinized $16 \mathrm{~h}$ after mechanical stress, washed twice with cold phosphate-buffered saline (PBS) $\left(4^{\circ} \mathrm{C}\right)$, resuspended in binding buffer containing $10 \mathrm{mM}$ HEPES/NaOH (pH 7.4), $140 \mathrm{mM} \mathrm{NaCl}, 2.5 \mathrm{mM} \mathrm{CaCl}_{2}$ and incubated with $5 \mu$ l FITC-labeled annexin $\mathrm{V}$ and $10 \mu \mathrm{l}$ propidium iodide (PI, stock solution $50 \mu \mathrm{g} / \mathrm{ml}$ ) for $15 \mathrm{~min}$ in the dark at room temperature. SMCs were analyzed by flow cytometry. After appropriate markings for negative and positive populations were set, the percentage of annexin $\mathrm{V}^{+} / \mathrm{PI}^{-}$ cells was determined and compared with unstressed controls.

\section{PI staining}

SMCs were harvested by trypsinization $24 \mathrm{~h}$ after mechanical stress. Cell pellets were resuspended in $200 \mu \mathrm{l} 0.1 \%$ Triton $\mathrm{X}-100 / 0.1 \% \mathrm{NaN}_{3} / \mathrm{H}_{2} \mathrm{O}$ and stained with $50 \mu \mathrm{g} / \mathrm{ml}$ propidium iodide (Sigma, St. Louis, Mo.) at $4^{\circ} \mathrm{C}$ for $30 \mathrm{~min}$. Cellular PI fluorescence signal was recorded on the FL2 channel of a FACS scan flow cytometer (Program Cell Quest, Becton Dickinson, Mountain View, Calif.). The number of apoptotic cells in the sub-G1 peak was indicated by lower fluorescence intensity and expressed as percentage of total events (5000 events/measurement).

\section{Stable transfection}

MKP-1 cDNA was isolated from a rat lung cDNA library by Liu et al. (20); plasmids expressing dominant negative rac1 were provided by Dr. G. Baier (Institute for Medical Biology and Human Genetics, University of Innsbruck, Austria). Rat SMCs were stably transfected with N17 rac (pEF-rac1 N17) and rMKP-1 (pSG5-rMKP1) plasmids, respectively, using a SuperFect Kit (Qiagen, Chatsworth, Calif.). Transfected cells were cultured overnight, divided one to four, and placed in culture medium supplemented with $150 \mu \mathrm{g} / \mathrm{ml}$ G418 (Sigma) to guarantee selection of cells carrying a neomycin-resistant 
plasmid. MKP-1- and rac N17-transfected SMCs were identified by Northern blotting and/or Western blotting, as described previously (21). Transfected cells were used for experiments on passages 20 to 30 .

\section{Protein extraction}

After strain stress, SMCs were washed twice with cold PBS $\left(4^{\circ} \mathrm{C}, \mathrm{pH} 7.4\right)$ and harvested on ice in buffer A containing 20 mM HEPES ( $\mathrm{pH}$ 7.4), $2 \mathrm{mM}$ EDTA, $50 \mathrm{mM} \beta$-glycerophosphate, $1 \mathrm{mM}$ DTT, $1 \mathrm{mM} \mathrm{Na} \mathrm{VO}_{4}, 1 \%$ Triton X-100, $10 \%$ glycerol, $1 \mu \mathrm{g} / \mathrm{ml}$ leupeptin, $1 \mu \mathrm{g} / \mathrm{ml}$ aprotinin, and $100 \mu \mathrm{M}$ PMSF. The suspension was incubated on ice for $20 \mathrm{~min}$ with vortexing every $5 \mathrm{~min}$. Cellular debris was pelleted by centrifugation for $30 \mathrm{~min}$ at $13,000 \mathrm{rpm}$ (Heraeus centrifuge) at $4^{\circ} \mathrm{C}$, supernatants were collected, and protein concentration was measured by the Bio-Rad assay (Bio-Rad Laboratories, Hercules, Calif.). Membrane protein isolation for rac expression was performed according to this method with slight modifications for membrane preparation, as described (21). Briefly, SMCs were washed in cold PBS $\left(4^{\circ} \mathrm{C}\right)$, scraped, pelleted, and resuspended in $500 \mu \mathrm{l}$ of homogenizing buffer (HB) (25 mM HEPES, $1 \mathrm{mM}$ EDTA, $1 \mu \mathrm{g} / \mathrm{ml}$ leupeptin, pepstatin A, and $0.1 \mathrm{mM}$ PMSF). Cells were sonicated for $10 \mathrm{~s}$ and centrifuged at 2,000 rpm for $10 \mathrm{~min}$ to remove debris. After centrifugation at $55,000 \times g$ for $1 \mathrm{~h}$ at $4^{\circ} \mathrm{C}$, the supernatant was removed and the membrane pellet was resuspended in $50 \mu \mathrm{l}$ of $\mathrm{HB}$, sonicated for $10 \mathrm{~s}$, and protein concentration was measured.

\section{Western blot analysis}

The procedure used for Western blot analysis was similar to that described elsewhere (21). Briefly, 50-150 $\mu \mathrm{g}$ of proteins were separated by electrophoresis through a $10-12 \%$ sodium dodecyl sulfate (SDS)-polyacrylamide gel and transferred onto nitrocellulose membranes. For Western blot of rac, 30-100 $\mu \mathrm{g}$ membrane protein was used in reduced conditions $\left(2.5 \% \mathrm{SDS} / 250 \mu \mathrm{M}\right.$ DTT for $5 \mathrm{~min}$ at $\left.90^{\circ} \mathrm{C}\right)$. Blots were probed with antibodies against phosphorylated p38 MAPK, pan p38 and MKP-1 (Santa Cruz Biochemicals, Santa Cruz, Calif.) or myc-tagged rac1 (a gift from Dr. G. Baier, Innsbruck). Reactions were visualized by ECL Western blot Detection Kit (Amersham) after incubation with peroxidase conjugates.

\section{Kinase assay}

The procedure for measuring kinase activity was also described previously (22). Briefly, p38 proteins were immunoprecipitated from the protein extracts. The p38 antibody used in our experiments was not cross-reactive with other MAPKs, as confirmed by its single band in Western blot analyses. p38 kinase activity was measured based on phosphorylation of myelin basic protein (MBP; $6 \mu \mathrm{g}$, Upstate Biotech. Inc., Lake placid, N.Y.) and $\gamma-\mathrm{P}^{32}$ ATP $(5 \mu \mathrm{Ci})$ for $20 \mathrm{~min}$, which has proved to be similar to HSP27 as a substrate (23). To stop the reaction, $15 \mu \mathrm{l}$ of $4 \times$ Laemmli buffer was added and the mixture was boiled for $5 \mathrm{~min}$. Protein kinase reactions were resolved by SDS-polyacrylamide gel electrophoresis (15\% gel) and subjected to autoradiography.

\section{Statistical analysis}

Statistical analyses were performed on a Macintosh computer with StatView SE + Graphics software. Analysis of variance was performed for multiple comparisons. An unpaired Student's $t$ test was used to assess differences between two groups. Results are given in means \pm standard deviations (SD). A $P$ value of less than 0.05 was considered statistically significant.

\section{RESULTS}

\section{Apoptosis in mouse vein grafts}

Consistent with our previous findings (16), the intima became largely acellular 1 wk after grafting, implicating a considerable loss of cells in grafted vein segments. Figure 1 shows typical examples of TUNEL $^{+}$cells. Quantitative analysis revealed a significant increase of $\mathrm{TUNEL}^{+}$nuclei in venous bypass grafts compared to normal venous vessels $1 \mathrm{wk}$ after implantation (13\% vs. $2 \%$ ). This marked increase in TUNEL $^{+}$cells peaked $4 \mathrm{wk}(29 \%)$ and declined $8 \mathrm{wk}$ (21\%) after grafting (Fig. $\mathbf{2 A}$ ). When apoptosis was corroborated by morphology such as concomitant condensation, lobulation, or fragmentation of the labeled nucleus on light and laser microscope levels, the maximal rate of apoptosis diminished to $6.4 \%$ (Fig. 2B) but was significantly higher than in freshly harvested veins $(0.5 \%)$.

To clarify the role of mechanical stress on SMC apoptosis, vein segments were grafted either to jugular veins or carotid arteries. Assessment of TUNEL ${ }^{+}$ nuclei on day 1 after the surgical procedure revealed significant differences (Fig. 3). Levels of apoptosis, as indicated by TUNEL staining, increased to $20 \%$ in
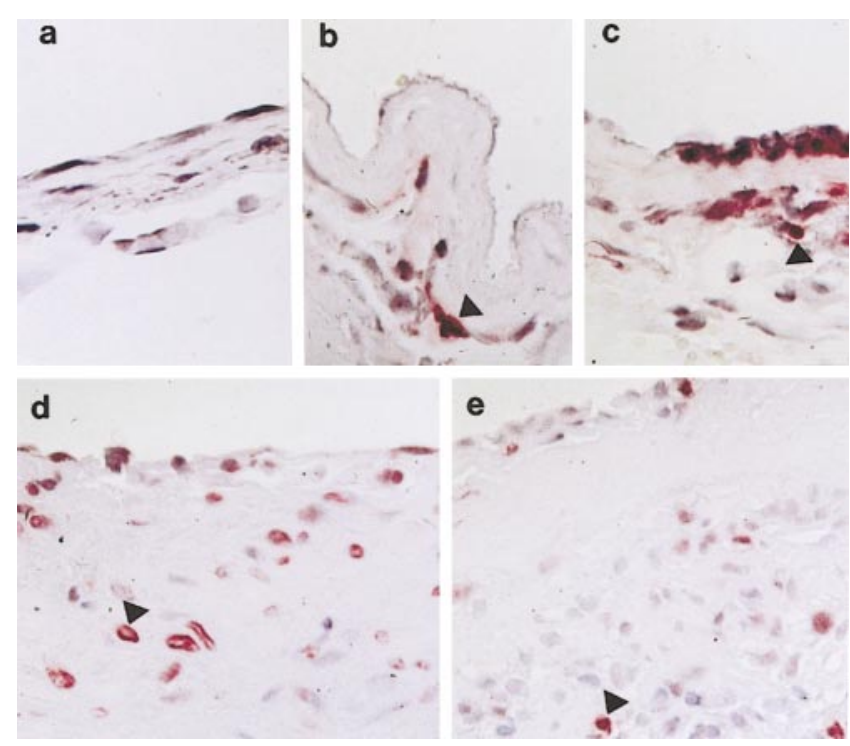

Figure 1. TUNEL-stained sections of mouse control vein $(a)$ and vein grafts harvested $1(b), 2(c), 4(d)$, and $8(e)$ wk after surgery. Mice underwent anesthesia and vena cava isografts into the common carotid artery. Grafted tissue fragments were harvested, fixed in $4 \%$ phosphate-buffered ( $\mathrm{pH} 7.2$ ) formaldehyde, embedded in paraffin, sectioned, and stained with TUNEL as described in Materials and Methods. Arrows indicate examples of $\mathrm{TUNEL}^{+}$cells in neointimal lesions; original magnification $\times 250$. 

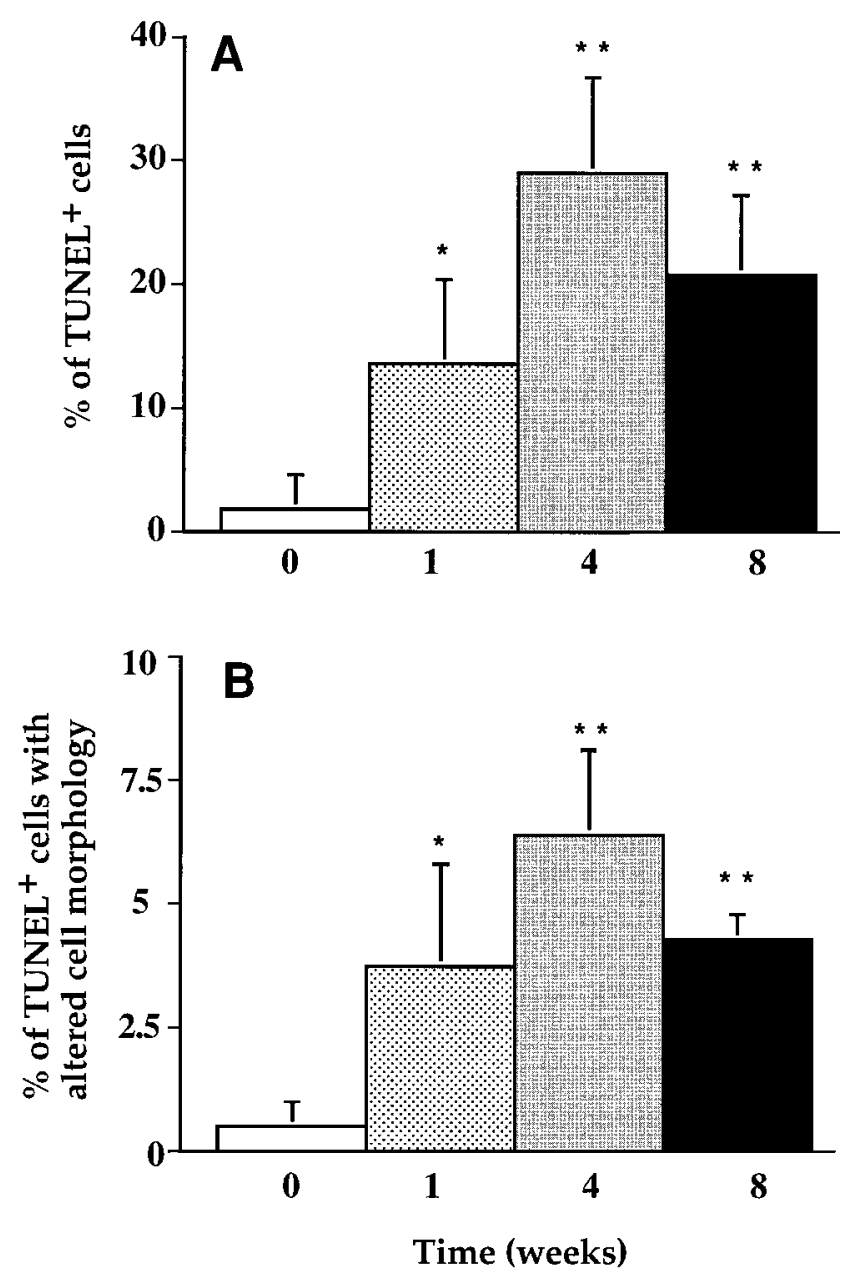

Figure 2. Statistical data of $\mathrm{TUNEL}^{+}$cells in vein grafts. TUNEL-stained sections were prepared as described in the legend to Fig. 1. TUNEL ${ }^{+}$and total nuclei in (neo)intima of veins were counted. The percentage of $\mathrm{TUNEL}^{+}$nuclei in groups 1,4 , and $8 \mathrm{wk}$, respectively $(A)$, and $\mathrm{TUNEL}^{+}$nuclei plus altered cell morphology $(B)$ were compared to control veins $(0 \mathrm{wk}) . * P<0.05, * * P<0.001$

vein to artery grafts, whereas vein-to-vein grafts manifested preserved cell viability $(3.6 \%)$ in their normal low pressure environment compared to normal venous vessels $(2 \%)$. By quantitating apoptotic cells with additional morphological criteria, the difference in the level of apoptosis remained significant ( $9 \%$ vs. $0.8 \%$ or $0.5 \%$ ). Less TUNEL-positive staining in vein-to-vein grafts underscores the possible role of mechanical stress in vascular cell apoptosis and suggests that the surgical procedure per se has little effect on overestimation of apoptosis.

\section{Cyclic strain stress-induced SMC apoptosis}

To explore the possibility that mechanical stress directly stimulates SMC apoptosis, rat aortic SMCs were cultivated on a flexible membrane and subjected to cyclic strain stress. Apoptotic cells were identified by double labeling with annexin $\mathrm{V}$ and PI.
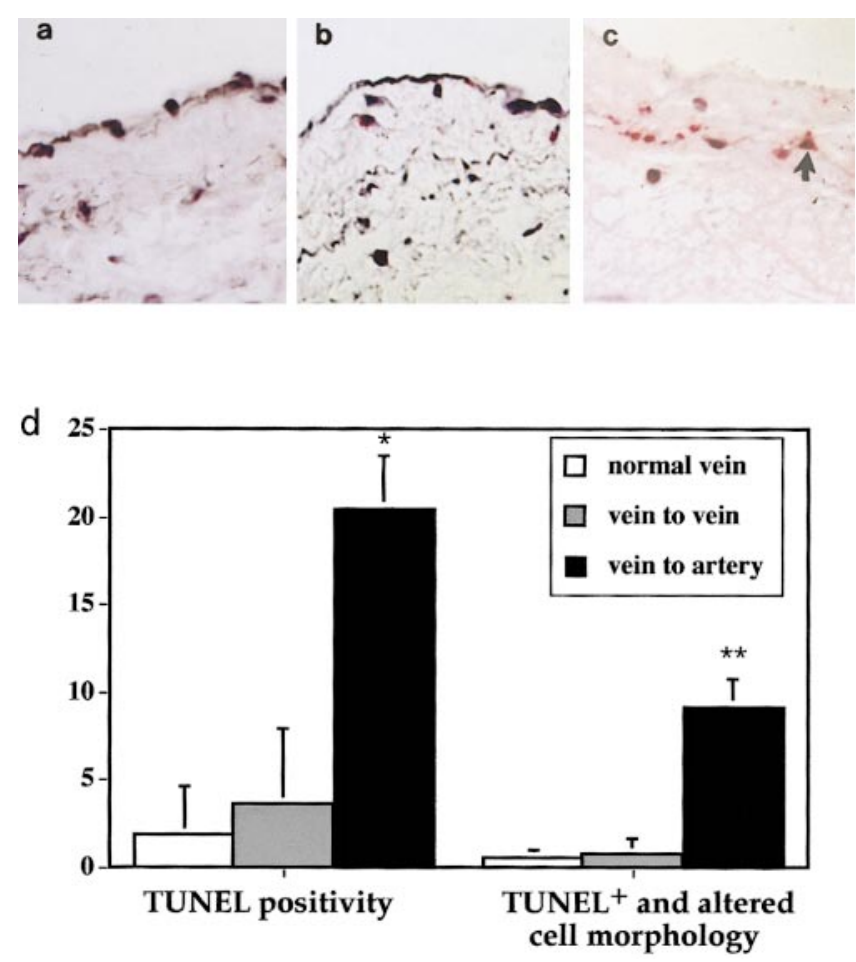

Figure 3. Comparison of TUNEL ${ }^{+}$cells between control veins and venous grafts implanted to veins or arteries. Vein segments $(a)$ were grafted to vein $(b)$ or artery $(c)$, harvested $24 \mathrm{~h}$ postoperatively, sectioned, and stained with a TUNEL kit. Panel $d$ shows statistical data $(n=6)$. Arrows indicate TUNEL $^{+}$nuclei. $* P<0.05, * * P<0.001$, original magnification $\times 250$.

PI labels all dead cells, including necrosis and final stages of apoptosis, whereas cells entering apoptosis are only stained by annexin V. Data shown in Fig. 4 indicate a time- and intensity-dependent induction of cell death in response to mechanical stress. Time course analysis (60 cycles/min, $15 \%$ elongation) revealed a two- to threefold increase in annexin V-FITC ${ }^{+} / \mathrm{PI}^{-}$cells $16 \mathrm{~h}$ after mechanical stress (Fig. $4 A$ ), reflecting an early stage of apoptosis. Further-
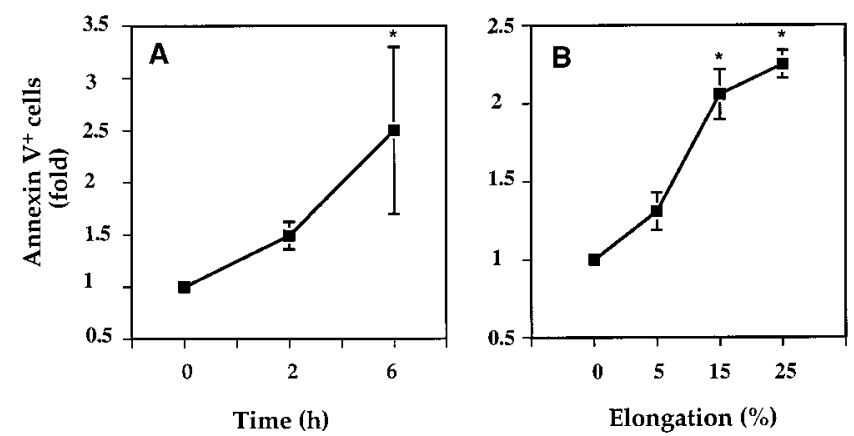

Figure 4. Time- and strength-dependent apoptosis of SMCs stimulated by cyclic strain stress. A) SMCs were treated with $15 \%$ elongation for 0,2 , and $6 \mathrm{~h}$, harvested, and stained with annexin V-FITC and PI $16 \mathrm{~h}$ after the onset of mechanical stress. B) SMCs were treated with cyclic strain stress at the indicated elongation for $6 \mathrm{~h}$. The results represent the mean \pm SD of three experiments. $* P<0.05$ 
more, apoptosis increased in SMCs subjected to cyclic strain stress $(60$ cycles/min, $6 \mathrm{~h}$ ) in a strengthdependent manner, reaching significant differences from unstressed controls above $5 \%$ elongation (Fig. $4 B)$. Changes in the rate of apoptosis were comparable in vascular SMCs of mouse, rat, and human (Fig. 5). After $24 \mathrm{~h}$, apoptosis almost doubled in strainstressed cells (60 cycles/min, $6 \mathrm{~h}, 10 \%$ elongation) compared to unstressed controls, although significant differences in spontaneous apoptosis/necrosis were observed among untreated SMCs of different species cultivated on elastomer bottomed plates.

In addition, mechanical stress-induced apoptosis was demonstrated by various techniques. PI-stained nuclei were analyzed by flow cytometry for DNA content. Apoptotic cells appeared in the sub- $\mathrm{G}_{1}$ region compared to viable cells due to DNA fragmentation (Fig. 6A). Consistent with these results, TUNEL positivity was observed only in stressed SMCs, but not in unstressed controls after $6 \mathrm{~h}$ of $15 \%$ stretch stress (Fig. $6 \mathrm{~B}$ ). One of the earliest features of cells undergoing apoptosis are changes in plasma membrane asymmetry, such as phosphatidylserine exposure. Therefore, annexin V staining can identify apoptosis at an earlier stage than assays based on nuclear changes, such as TUNEL and PI staining. Representative dot plots of annexin V staining are shown in Fig. 6C. Untreated cells were primarily annexin V-FITC ${ }^{-} / \mathrm{PI}^{-}$(lower left quadrant), indicating viable cells. After mechanical stress, a significant number of cells became annexin $\mathrm{V}-\mathrm{FITC}^{+} / \mathrm{PI}^{-}$ (lower right quadrant), reflecting early stages of apo-

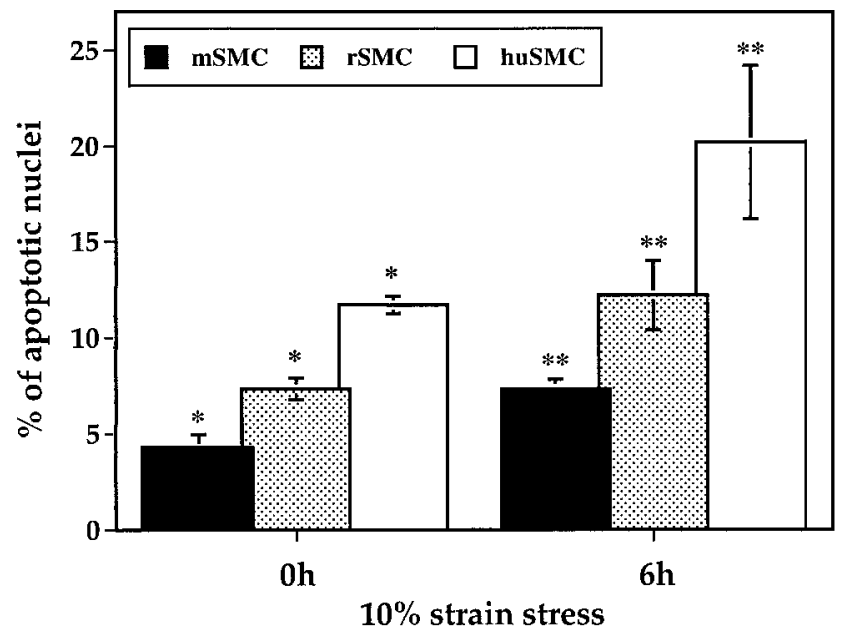

Figure 5. Mechanical stress-induced apoptosis in SMCs from different species. SMCs from mouse (mSMC), rat (rSMC), and human (huSMC) were stressed for $6 \mathrm{~h}$ and lysed with $0.1 \%$ Triton $\mathrm{X}-100 / 0.1 \% \mathrm{NaN}_{3} / \mathrm{H}_{2} \mathrm{O}$. Nuclei were labeled with PI for DNA fragmentation. Data represent the percentage of cells in the sub-G1 peak with or without strain stress treatment. Note the twofold increase of apoptosis induced by mechanical stress. The results represent the mean \pm SD of three experiments. *Significant difference among different species, $* *$ significant difference from unstressed SMCs, $P<$ 0.05
A
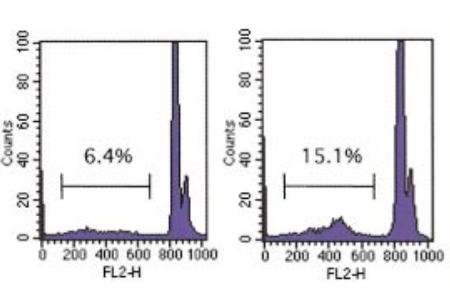

B

C
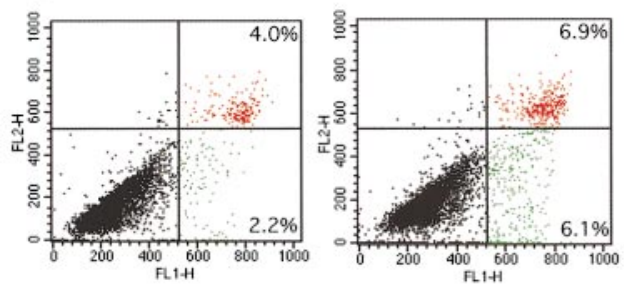

FL2-H

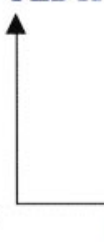

FL1-H

Figure 6. SMC apoptosis evidenced by various techniques. SMCs were stressed for $6 \mathrm{~h}$, harvested, and labeled with PI $(A)$, TUNEL $(B)$, and PI and annexin V double staining $(C)$. Representative FL2-histograms of stained nuclei indicate an increase from $6.4 \%$ to $15.1 \%$ in the sub-G $\mathrm{G}_{1}$ population $(A)$. Identification of apoptotic cells by TUNEL $(B)$. A cell smear of stressed-SMCs was stained with a TUNEL kit (green fluorescence) and counterstained with Hoechst 33342 (blue fluorescence). C) Typical fluorescence-1/fluorescence-2 profil of mechanical stressed-SMC ( $6 \mathrm{~h}, 15 \%$ elongation) stained with annexin $\mathrm{V}$ and PI. Note an increase in annexin V-FITC ${ }^{+} / \mathrm{PI}^{-}$and annexin $\mathrm{V}$-FITC ${ }^{+} / \mathrm{PI}^{+}$cells in the lower and upper right quadrants, respectively, reflecting early and late stages of apoptosis (right panel) compared to unstressed control (left panel).

ptosis. A population of cells progressing to late stages of apoptosis became double positive (upper right quadrant).

\section{Involvement of p38 MAPK in mechanical stress- induced apoptosis}

To elucidate the potential regulatory mechanisms that may lead to acute cell death after mechanical stress, levels of p38 MAPKs were analyzed in stretch-stressed SMCs by Western blot analyses using anti-phosphorylated-p38 MAPK antibodies. As shown in Fig. 7A, tensile stimuli resulted in increased p38 phosphorylation in SMCs stressed with elongation ranging from $5 \%$ to $30 \%$ of original size. Antibodies against pan-p38 indicated that similar amounts of proteins were loaded (bottom panel). Angiotensin II, a potent activator of all MAPKs in SMCs (24), served as positive control. A similar p38 activation was measured in kinase assays on phosphorylation of MBP as substrate. This p38 activity was markedly inhibited by $1 \mu \mathrm{M}$ of the specific inhibitor SB 202190 (Fig. $7 B$ ). Pretreatment with SB 202190 prevented mechanical stress-induced apoptosis, as identified by annexin $\mathrm{V}$ staining (Fig. 7C). No elevation of apoptosis was 
Elongation (\%) $\quad 0 \quad 5 \quad 15 \quad 30$ Ang II

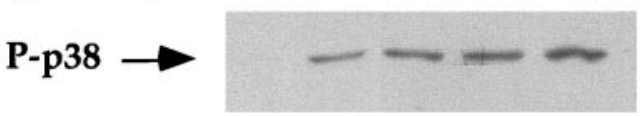

Elongation (\%) $\quad 0 \quad 5 \quad 15 \quad 30$ Ang II

B
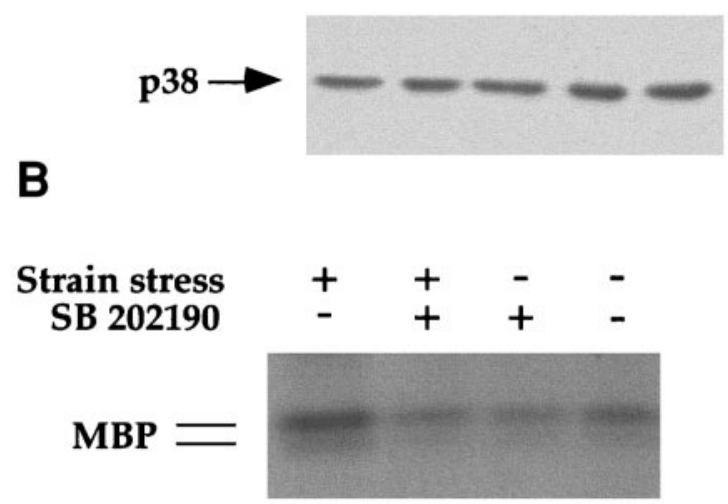

C

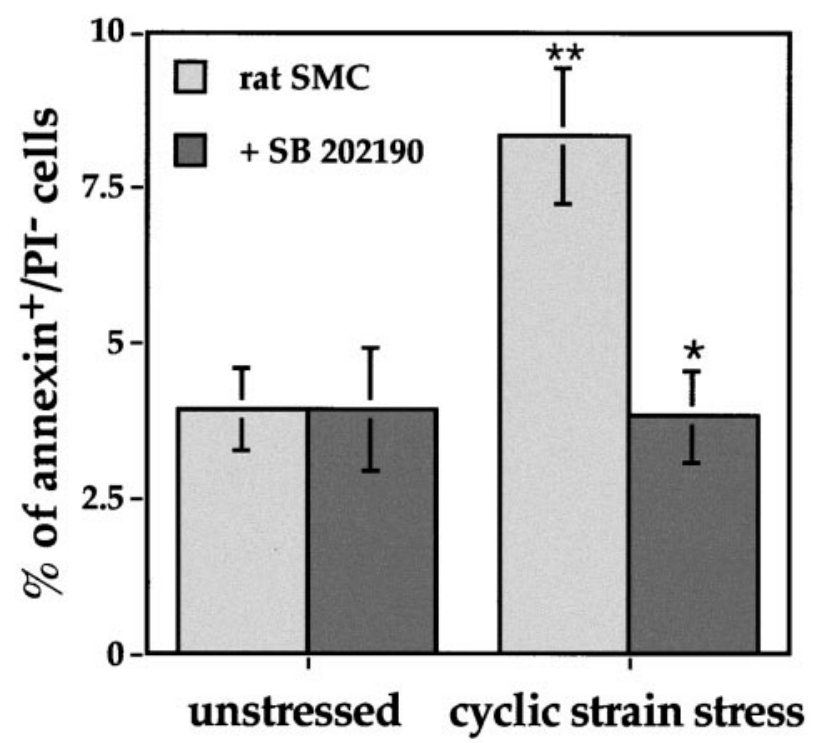

Figure 7. Mechanical stress-induced p38 activation and apoptosis. Rat SMCs were cultivated on flexible membranes and subjected to strain stress at the indicated elongation of original size for $10 \mathrm{~min}$. Cells were lysed in buffer immediately after mechanical stress. Protein extracts were separated on $10 \%$ SDS-polyacrylamide gel, transferred to membranes, and probed using antibody to phosphorylated p38 (A; P-p38). Quantity of total p38 protein was verified with antibody to pan-p38 (lower panel). Panel $B$ shows results of kinase assays for p38 in stressed and unstressed SMCs in the presence or absence of the p38 inhibitor SB $202190(1 \mu \mathrm{M})$, respectively. p38 MAPK activity was measured on phosphorylation of myelin basic protein (MBP) substrate. Panel $C$ represents flow cytometry analysis in the corresponding cells after staining with annexin $\mathrm{V}$ and propidium iodide (PI). **Significant difference compared to unstressed controls, *significant difference compared to positive controls, $P<0.05$ observed in unstressed cells in the presence of 1 $\mu \mathrm{M}$ SB202190 for $24 \mathrm{~h}$. Thus, p38 MAPKs are required for the transduction of apoptotic signals in response to mechanical stress.

To provide further evidence for the importance of p38 MAPK pathways, we investigated the effects of upstream and downstream signal transducers in MAPK signaling and apoptosis: Rac, a member of the ras superfamily of small GTP binding proteins (25), is considered to be a key transducer in various MAPK signaling events. Therefore, SMCs were stably transfected with expression vectors encoding a myc-tagged form of a dominant negative rac 1 (rac1 N17). The expression vector also contained the selectable marker gene, neo, to select multiple G418-resistant colonies. Transfected clones stably expressing rac-1 N17 were identified by Western blotting using anti-myc-tag antibodies (Fig. 8A). As shown in Fig. 8B, increased phosphorylation of p38 was observed in vector controls, whereas phosphorylated p38 levels were almost undetectable in rac1 N17-transfected cell lines, indicating significant blocking of p38 activation induced by strain stress. Concomitantly, the production of a large quantity of a potent
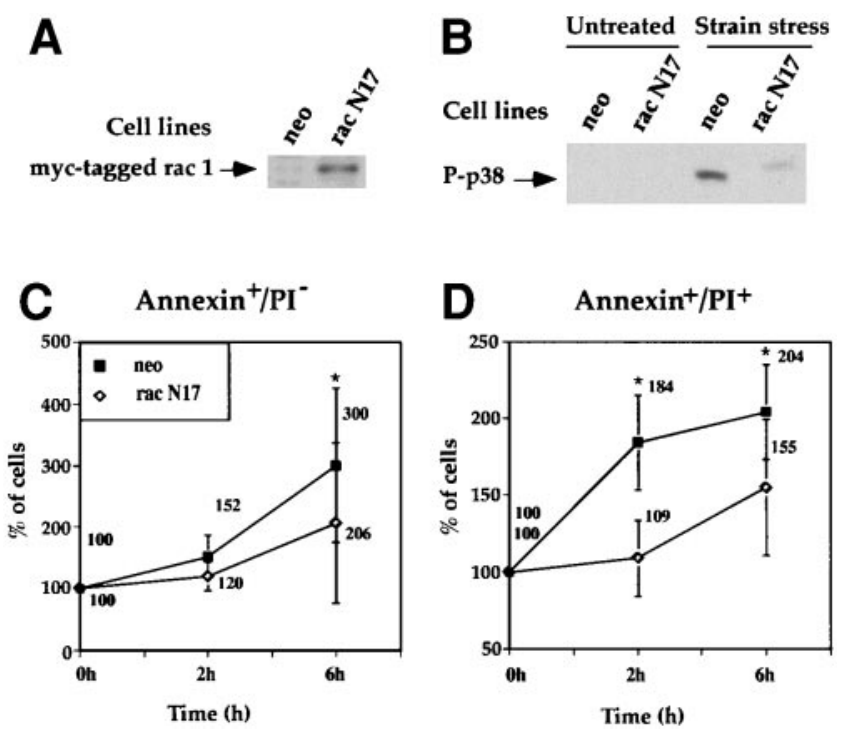

Figure 8. Rac-dependent p38 activation and apoptosis. Rat SMCs were stably transfected with dominant negative rac (rac1 N17) or vector (neo) using the Superfect reagent. The experimental procedures for establishing rac1 N17 or vectortransfected cell lines are described in Materials and Methods. SMCs expressing rac1 N17 were identified in Western blot analysis using anti-myc tag antibody $(A)$. SMC lines were treated with mechanical stress for $10 \mathrm{~min}$, protein extracts were harvested and probed with antibody for phosphorylatedp38 $(B)$. Stressed cells were analyzed in the flow cytometer $16 \mathrm{~h}$ after onset of mechanical stress by annexin $\mathrm{V}$ and PI staining. In both cell lines, the increase in annexin $\mathrm{V}^{+} / \mathrm{PI}^{-}$ $(C)$ and annexin $\mathrm{V}^{+} / \mathrm{PI}^{+}$cells $(D)$ was compared to unstressed controls, respectively. Each point in the histogram represents mean \pm SD of three experiments. *Significant difference from vector SMC lines, $P<0.05$ 
A
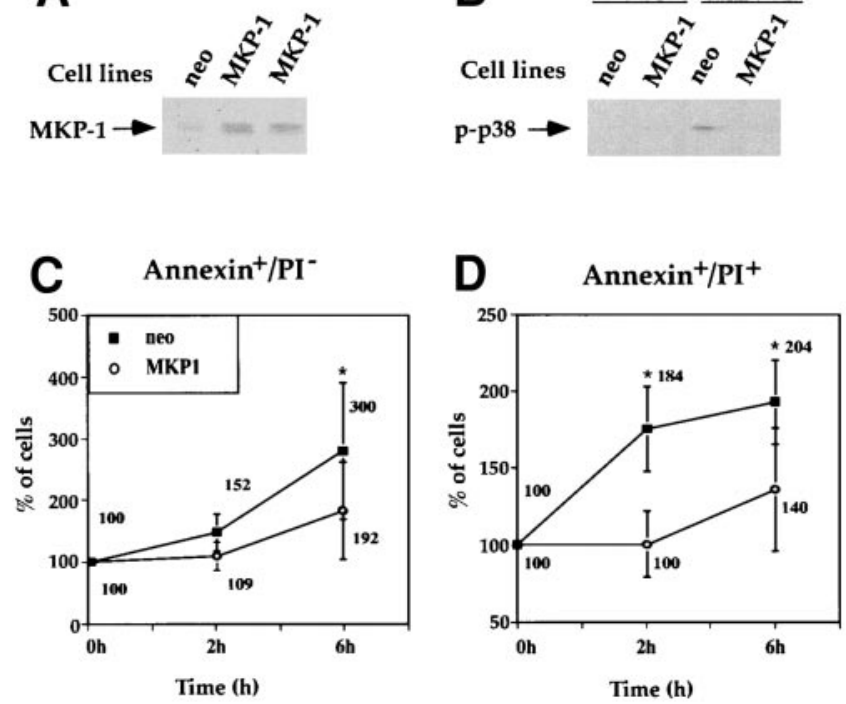

Figure 9. Overexpression of MKP-1 inhibited p38 activation and SMC apoptosis. Rat SMCs lines transfected with constructs overexpressing MKP-1 (MKP-1) or vector (neo) were established using the same procedure as described in Materials and Methods. Panel $A$ shows results of Western blot analysis using the anti-MKP-1 antibody to identify MKP-1 overexpressing cell lines. As described in the legend to Fig. 8, mechanical stress-induced activation of p38 in transfected cell lines was demonstrated in Western blot analysis using antibodies to phosphorylated-p38 $(B)$ and changes in annexin $\mathrm{V}$ and PI staining after mechanical stress were detected by flow cytometry analysis. Panels $C$ and $D$ represent the increase of annexin $\mathrm{V}^{+} / \mathrm{PI}^{-}$and annexin $\mathrm{V}^{+} / \mathrm{PI}^{+}$cells in both cell lines. Each point in the histogram represents mean \pm SD of three experiments. *Significant difference from vector SMC lines, $P$ $<0.05$

dominant negative mutated form of rac1 markedly reduced mechanical stress-induced apoptosis compared to vector-transfected SMCs (Fig. 8C, D). Since MAPK phosphatase-1 (MKP-1) specifically inactivates all three MAPKs, including p38, we assessed the effects of MKP-1 overexpression on SMC apoptosis. Transfected clones stably expressing MKP-1 were identified by Western blotting and showed high MKP-1 expression (Fig. 9A). In comparison to cells transfected with vector, p38 phosphorylation was significantly reduced in MKP-1transfected SMCs (Fig. 9B). Quantification of optical densities from autoradiograms of three experiments revealed a 13-fold increase of phosphorylated p38 in vector cells after cyclic strain stress compared to unstressed controls, but only a minor change in stressed MKP-1-transfected cells. Inhibition of p38 activation was again associated with a marked decrease in apoptosis, as evidenced by annexin V/PI staining, suggesting that MAPK activation is a critical determinant for SMC apoptosis stimulated by biomechanical stress (Fig. $9 C, D)$.

\section{DISCUSSION}

Why spontaneous atherosclerosis occurs in the arterial wall, but not in the vein vessel, is an important question that remains to be answered. Indeed, accelerated arteriosclerosis develops rapidly in venous bypass grafts, which bear increased biomechanical forces due to alterations in blood pressure, i.e., vein $(0-30 \mathrm{~mm} \mathrm{Hg})$ vs. artery $(120 \mathrm{~mm} \mathrm{Hg})$. In the present study, we demonstrate that biomechanical stress evokes apoptosis in vein grafts, followed by neointimal lesion formation. Therefore, we hypothesize that biomechanical stress is an initiator of cell death evoking an inflammatory response in the venous wall, followed by SMC proliferation and development of arteriosclerotic lesion in grafted veins.

Investigations on the pathogenesis of vein graft disease have been conducted primarily on cell proliferation (3), and little is known about the role of cell death in disease development. Our findings provide solid evidence that one of the earliest cellular events in neointima formation in vein grafts is cell apoptosis, and our in vivo and in vitro experiments demonstrate for the first time that mechanical stress is a critical initiator of SMC apoptosis. Based on our observations in the murine vein graft model, a large portion of cells within grafted vessels become apoptotic in the first week. Concomitantly, a marked loss of SMCs has been observed in early lesions of human vein grafts $(4,16,26)$. Necrosis cannot be excluded in this process, particularly in vivo, because cell death by nonapoptotic mechanisms is also TUNEL positive when extensive DNA breaks have occurred (27). Thus, elevated biomechanical force is primarily responsible for cell death, an early event in the pathogenesis of vein graft disease.

Massive mononuclear cell infiltration into the vessel wall follows cell death between 1 and 4 wk after engraftment. Recently, we found that intimal lesions in vein isografts performed in ICAM- $1-/-$ mice were reduced up to $50 \%$ compared to wild-type controls, implicating the importance of mononuclear cell recruitment for the development of neointimal hyperplasia (Y. Zou et al., unpublished observations). The mechanism by which monocytes/ macrophages are continuously recruited to the neointima of vein bypass grafts is not fully understood $(28,29)$. Although apoptosis is believed to rarely evoke inflammation responses in tissues (30, 31 ), apoptotic cells release the S19 ribosomal protein dimer (32), a chemokine for macrophages/ monocytes, by molecular mimicry to complement C5a (33). The infiltrating cells might remove apoptotic bodies $(34,35)$, and paracrine stimuli such as cytokine secretion during phagocytosis could enhance infiltration and initiate an overwhelming repair mechanism. If cell death in vein grafts is par- 
tially induced by necrosis, cell death may be a primary force for the induction of inflammatory responses in grafted veins.

Abundant evidence indicates that SMC accumulation and matrix protein deposition are major components of neointimal lesions in late-stage vein grafts (36). The molecular mechanisms of SMC proliferation in vivo remain to be elucidated. Given the fact that SMC accumulation in the intima occurs $4 \mathrm{wk}$ postoperatively, we postulate three possibilities. 1) Phenotypic selection: the phenotype of neointimal SMCs differs from medial SMCs, increased resistance against apoptosis being one of their striking features (37). Elevated biomechanical forces result in apoptosis of a large portion of SMCs. The small remaining population of SMCs can sustain the arterial blood pressure and may rapidly expand to form neointima. 2) Inflammatory response: monocytes/macrophages in vein grafts can release a panel of cytokines and growth factors, such as transforming growth factor- $\beta$ and fibroblast growth factor, which lead to SMC migration and proliferation (38). 3) Mechanical stress as mitogen: mechanical forces stimulate the expression and release of platelet-derived growth factors (PDGFs) $(39,40)$ and induce PDGF receptor phosphorylation or activation in SMCs $(15,41)$. Therefore, PDGF production and their receptor activation play a pivotal role in initiating SMC migration and proliferation.

MAPKs have been implicated in both regulation of cell proliferation and cell death (8-11), which underscores their possible importance in vein graft disease. We documented previously that PDGF receptor $\alpha$ is phosphorylated and activated in response to mechanical stimuli whereby mechanical forces initiate signaling pathways normally used by growth factors such as ras-raf-MEK-ERK activation, followed by enhanced DNA binding activity of transcription factor AP-1 (15). In the present study, we describe another mechanical stress-induced signal pathway involving rac and p38 MAPKs. Activation of p38 MAPKs occurs in a variety of extracellular stressors including osmotic shock, UV irradiation, exposure to cytokines, and endotoxin $(7,9)$. A novel finding in the present study is that p38-mediated signaling plays a crucial role in apoptosis after cyclic strain stress. Mechanical stress-induced apoptosis declined by pretreatment with p38 MAPK inhibitor or in transfected cell lines that inactivate or inhibit p38 phosphorylation. It should be noted that the transfectants failed to result in complete inhibition of apoptosis induced by mechanical stress. Therefore, other signal transduction pathways, such as JNK/SAPK or cross talk between ERK and p38 signaling, may contribute to direct modulation of signal transductions leading to apoptosis during mechanical stress. Taken together, our findings suggest that p38 is a crucial signal transducer for SMC apoptosis in response to mechanical stress and that activation of p38 MAPKs in grafted vessels might play a significant role in mediating cell apoptosis.

What initiates p38 activation after mechanical stress? PDGF receptors cannot be regarded as candidates because the growth factor receptor antagonist suramin does not block p38 activation, but rather enhances its activation (41a). Integrins that bind to collagen or flexible membrane might be activated in response to mechanical stress (42), a notion supported by the observation that integrins are involved in JNK/SAPK activation in endothelial cells stimulated by shear stress $(43,44)$. Further studies to identify other mechanosensors will significantly enhance our understanding of biomechanical stress-induced vascular remodeling. In addition, the downstream mediators of p38-dependent apoptosis are poorly characterized, but there is evidence that p38 MAPK contributes to phosphorylation of p53 (45). p53 activation has been implicated in cell cycle control, DNA repair, and apoptosis $(46,47)$ by up-regulating Fas/Apo1 (48) and Bax expression (49).

In summary, our results suggest that biomechanical stress rapidly induces SMC apoptosis in vivo and in vitro, in which p38 MAPKs play a pivotal role in signal transduction leading to apoptosis in response to mechanical stimuli. We hypothesize that cell death is one of the earliest cellular events that evokes an inflammatory response, followed by SMC proliferation. Vascular cell apoptosis and proliferation coincide in the development of arteriosclerotic lesions. The balance between these two processes, i.e., proliferation/apoptosis, is a determinant during vessel remodeling. If the balance can be modified arbitrarily, e.g., by inhibiting (50) or enhancing apoptosis (51) at different stages of vessel grafts, new strategies for prevention and treatment of vein graft disease may be achieved.

This work was supported by grants P-12568-MED and P-13099-BIO (to Q.X.) from the Austrian Science Fund, and P7919 (to Q.X.) from the Austrian National Bank. We are grateful to Dr. G. Wick for his continuous support. We thank Drs. N. J. Holbrook and Y. Liu (National Institute on Aging, Baltimore, Md.) for providing MKP-1 plasmid, Dr. G. Baier (Institute for Medical Biology and Human Genetics, University of Innsbruck, Innsbruck, Austria) for kindly providing the dominant negative Rac1 N17 plasmids and antibody against myc-tag, and A. Jenewein for excellent technical assistance.

\section{REFERENCES}

1. Motwani, J. G., and Topol, E. J. (1998) Aortocoronary saphenous vein graft disease: pathogenesis, predisposition, and prevention. Circulation 97, 916-931

2. Gibbons, G. H., and Dzau, V.J. (1994) The emerging concept of vascular remodeling. N. Engl. J. Med. 330, 1431-1438 
3. Yang, Z., Oemar, B. S., Carrel, T., Kipfer, B., Julmy, F., and Luscher, T. F. (1998) Different proliferative properties of smooth muscle cells of human arterial and venous bypass vessels: role of PDGF receptors, mitogen-activated protein kinase, and cyclin-dependent kinase inhibitors. Circulation 97, 181-187

4. Kockx, M. M., Cambier, B. A., Bortier, H. E., De Meyer, G. R., Declercq, S. C., van Cauwelaert, P. A., and Bultinck, J. (1994) Foam cell replication and smooth muscle cell apoptosis in human saphenous vein grafts. Histopathology 25, 365-371

5. Geng, Y. J., Wu, Q., Muszynski, M., Hansson, G. K., and Libby, P. (1996) Apoptosis of vascular smooth muscle cells induced by in vitro stimulation with interferon- $\gamma$, tumor necrosis factor- $\alpha$, and interleukin-1 ß. Arterioscler. Thromb. Vasc. Biol. 16, 19-27

6. Best, P. J. M., Hasdai, D., Sangiorgi, G., Schwartz, R. S., Holmes, D. R., Jr., Simari, R. D., and Lerman, A. (1999) Apoptosis. Basic concepts and implications in coronary artery disease. Arterioscler. Thromb. Vasc. Biol. 19, 14-22

7. Zou, Y., Hu, Y., Metzler, B., and Xu, Q. (1998) Signal transduction in arteriosclerosis: mechanical stress-activated MAP kinases in vascular smooth muscle cells (review). Int. J. Mol. Med. 1, $827-834$

8. Lehoux, S., and Tedgui, A. (1998) Signal transduction of mechanical stresses in the vascular wall. Hypertension 32, 338345

9. Force, T., Pombo, C. M., Avruch, J. A., Bonventre, J. V., and Kyriakis, J. M. (1996) Stress-activated protein kinases in cardiovascular disease. Circ. Res. 78, 947-953

10. Chien, S., Li, S., and Shyy, J. Y. J. (1998) Effects of mechanical forces on signal transduction and gene expression in endothelial cells. Hypertension 31, 162-169

11. Ip, Y. T., and Davis, R. J. (1998) Signal transduction by the c-Jun N-terminal kinase (JNK) - from inflammation to development. Curr. Opin. Cell Biol. 10, 205-219

12. Hu, Y., Cheng, L., Hochleitner, B. W., and Xu, Q. (1997) Activation of mitogen-activated protein kinases (ERK/JNK) and AP-1 transcription factor in rat carotid arteries after balloon injury. Arterioscler. Thromb. Vasc. Biol. 17, 2808-2816

13. Xu, Q., Liu, Y., Gorospe, M., Udelsman, R., and Holbrook, N. J. (1996) Acute hypertension activates mitogen-activated protein kinases in arterial wall. J. Clin. Invest. 97, 508-514

14. Metzler, B., Li, C., Hu, Y., Sturm, G., and Ghaffari-Tabrizi, N., Xu, Q. (1999) LDL stimulates mitogen-activated protein kinase phosphatase-1 expression, independent of LDL receptors, in vascular smooth muscle cells. Arterioscler. Thromb. Vasc. Biol. 19, 1862-1871

15. Hu, Y., Böck, G., Wick, G., and Xu, Q. (1998) Activation of PDGF receptor $\alpha$ in vascular smooth muscle cells by mechanical stress. FASEB J. 12, 1135-1142

16. Zou, Y., Dietrich, H., Hu, Y., Metzler, B., Wick, G., and Xu, Q. (1998) Mouse model of venous bypass graft arteriosclerosis. Am. J. Pathol. 153, 1301-1310

17. Xu, Q., Li, D. G., Holbrook, N. J., and Udelsman, R. (1995) Acute hypertension induces heat-shock protein 70 gene expression in rat aorta. Circulation 92, 1223-1229

18. Hu, Y., Zou, Y., Dietrich, H., Wick, G., and Xu, Q. (1999) Inhibition of neointima hyperplasia of mouse vein grafts by locally applied suramin. Circulation 100, 861-868

19. Banes, A. J., Gilbert, J., Taylor, D., and Monbureau, O. (1985) A new vacuum-operated stress-providing instrument that applies static or variable duration cyclic tension or compression to cells in vitro. J. Cell Sci. 75, 35-42

20. Liu, Y., Gorospe, M., Yang, C., and Holbrook, N. J. (1995) Role of mitogen-activated protein kinase phosphatase during the cellular response to genotoxic stress. Inhibition of c-Jun Nterminal kinase activity and AP-1-dependent gene activation. J. Biol. Chem. 270, 8377-8380

21. Li, C., Hu, Y., Mayr, M., and Xu, Q. (1999) Cyclic strain stress-induced mitogen-activated protein kinase (MAPK) phosphatase 1 expression in vascular smooth muscle cells is regulated by ras/rac-MAPK pathways. J. Biol. Chem. 274, 25273-25280

22. Liu, Y., Guyton, K. Z., Gorospe, M., Xu, Q., Lee, J. C., and Holbrook, N. J. (1996) Differential activation of ERK, JNK/ SAPK and P38/CSBP/RK MAP kinase family members during the cellular response to arsenite. Free Rad. Biol. Med. 21, $771-781$
23. Wang, X., Martindale, J. L., Liu, Y., and Holbrook, N. J. (1998) The cellular response to oxidative stress: influences of mitogenactivated protein kinase signalling pathways on cell survival. Biochem J. 333, 291-300

24. Takahashi, E., and Berk, B. C. (1998) MAP kinases and vascular smooth muscle function. Acta Physiol. Scand. 164, 611-621

25. Ridley, A. (1999) Rac and Rho. Curr. Biol. 9, 156

26. Mautner, S. L., Mautner, G. C., Hunsberger, S. A., and Roberts, W. C. (1992) Comparison of composition of atherosclerotic plaques in saphenous veins used as aortocoronary bypass conduits with plaques in native coronary arteries in the same men. Am. J. Cardiol. 70, 1380-1387

27. Schwartz, S. M., and Bennett, M. R. (1995) Death by any other name. Am. J. Pathol. 147, 229-234

28. Okada, M., Matsumori, A., Ono, K., Furukawa, Y., Shioi, T., Iwasaki, A., Matsushima, K., and Sasayama, S. (1998) Cyclic stretch upregulates production of interleukin-8 and monocyte chemotactic and activating factor/monocyte chemoattractant protein-1 in human endothelial cells. Arterioscler. Thromb. Vasc. Biol. 18, 894-901

29. Furukawa, Y., Matsumori, A., Ohashi, N., Shioi, T., Ono, K., Harada, A., Matsushima, K., and Sasayama, S. (1999) Antimonocyte chemoattractant protein-1/monocyte chemotactic and activating factor antibody inhibits neointimal hyperplasia in injured rat carotid arteries. Circ. Res. 84, 306-314

30. Granville, D. J., Carthy, C. M., Hunt, D. W. C., and McManus, B. M. (1998) Apoptosis: Molecular aspects of cell death and disease. Lab. Invest. 78, 893-913

31. Bennett, M. R., and Boyle, J. J. (1998) Apoptosis of vascular smooth muscle cells in atherosclerosis. Atherosclerosis 138, 3-9

32. Horino, K., Nishiura, H., Ohsako, T., Shibuya, Y., Hiraoka, T., Kitamura, N., and Yamamoto T. (1998) A monocyte chemotactic factor, S19 ribosomal protein dimer, in phagocytic clearance of apoptotic cells. Lab. Invest. 78, 603-617

33. Nishiura, H., Shibuya, Y., and Yamamoto, T. (1998) S19 ribosomal protein cross-linked dimer causes monocyte-predominant infiltration by means of molecular mimicry to complement C5a. Lab. Invest. 78, 1615-1623

34. Björkerud, S., and Björkerud, B. (1996) Apoptosis is abundant in human atherosclerotic lesions, especially in inflammatory cells (macrophages and $\mathrm{T}$ cells), and may contribute to the accumulation of gruel and plaque instability. Am. J. Pathol. 149, $367-380$

35. Isner, J. M., Kearney, M., Bortman, S., and Passeri, J. (1995) Apoptosis in human atherosclerosis and restenosis. Circulation 91, 2703-2711

36. Newby, A. C., and George, S. J. (1996) Proliferation, migration, matrix turnover, and death of smooth muscle cells in native coronary and vein graft atherosclerosis. Curr. Opin. Cardiol. 11, 574-582

37. Pollman, M. J., Hall, J. L., and Gibbons, G. H. (1999) Determinants of vascular smooth muscle cell apoptosis after balloon angioplasty injury: Influence of redox state and cell phenotype. Circ. Res. 84, 113-121

38. Bryant, S. R., Bjercke, R. J., Erichsen, D. A., Rege, A., and Lindner, V. (1999) Vascular remodeling in response to altered blood flow is mediated by fibroblast growth factor-2. Circ. Res. 84, 323-328

39. Wilson, E., Mai, Q., Sudhir, K., Weiss, R. H., and Ives, H. E. (1993) Mechanical strain induces growth of vascular smooth muscle cells via autocrine action of PDGF. J. Cell Biol. 123, 741-747

40. Sumpio, B. E., Du, W., Galagher, G., Wang, X., Khachigian, L. M., Collins, T., Gimbrone, M. A., Jr., and Resnick, N. (1998) Regulation of PDGF-B in endothelial cells exposed to cyclic strain. Arterioscler. Thromb. Vasc. Biol. 18, 349-355

41. Abe, J., Deguchi, J., Matsumoto, T., Takuwa, N., Noda, M., Ohno, M., Makuuchi, M., Kurokawa, K., and Takuwa, Y. (1997) Stimulated activation of platelet-derived growth factor receptor in vivo in balloon-injured arteries: a link between angiotensin II and intimal thickening. Circulation 96, 1906-1913

41a. Li, C., Hu, Y., Sturm, G., Wick, G., and Xu, Q. (2000) Ras/racdependent activation of p38 mitogen-activated protein kinases in smooth muscle cells stimulated by cyclic strain stress. Arterioscler. Thromb. Vasc. Biol. In press

42. Wilson, E., Sudhir, K., and Ives, H. E. (1995) Mechanical strain of rat vascular smooth muscle cells is sensed by specific extra- 
cellular matrix/integrin interactions. J. Clin. Invest. 96, 23642372

43. Ishida, T., Peterson, T. E., Kovach, N. L., and Berk, B. C. (1996) MAP kinase activation by flow in endothelial cells: role of $\beta 1$ integrins and tyrosine kinases. Circ. Res. 79, 310-316

44. Shyy, J. Y. J., and Chien, S. (1997) Role of integrins in cellular responses to mechanical stress and adhesion. Curr. Opin. Cell Biol. 9, 707-713

45. Huang, C., Ma, W. Y., Maxiner, A., Sun, Y., and Dong, Z. (1999) p38 kinase mediates UV-induced phosphorylation of p53 protein at serine $389^{*}$. J. Biol. Chem. 274, 12229-12235

46. Bennett, M. R., Macdonald, K., Chan, S. W., Boyle, J. J., and Weissberg, P. L. (1998) Cooperative interactions between RB and p53 regulate cell proliferation, cell senescence, and apoptosis in human vascular smooth muscle cells from atherosclerotic plaques. Circ. Res. 82, 704-712

47. Bennett, M. R., Evan, G. I., and Schwartz, S. M. (1995) Apoptosis of rat vascular smooth muscle cells is regulated by p53-dependent and -independent pathways. Circ. Res. 77, 266-273
48. Bennett, M. R., Macdonald, K., Chan, S. W., Luzio, J. P., Simari, R., and Weissberg, P. L. (1998) Cell surface trafficking of Fas: a rapid mechanism of p53-mediated apoptosis. Science 282, 290-293

49. Miyashita, T., and Reed, J. C. (1995) Tumor suppressor p53 is a direct transcriptional activator of the human bax gene. Cell 80, 293-299

50. Mehta, D., George, S. J., Jeremy, J. Y., Izzat, M. B., Southgate, K. M., Bryan, A. J., Newby, A. C., and Angelini, G. D. (1998) External stenting reduces long-term medial and neointimal thickening and platelet derived growth factor expression in a pig model of arteriovenous bypass grafting. Nat. Med. 4, 235-239

51. Pollman, M. J., Hall, J. L., Mann, M. J., Zhang, L., and Gibbons, G. H. (1998) Inhibition of neointimal cell bcl-x expression induces apoptosis and regression of vascular disease. Nat. Med. 4, 222-227

Received for publication June 21, 1999. Revised for publication October 6, 1999. 